\title{
Analysis on the spring's fatigue life of spring vent
}

$$
\text { Xu Fangxin }{ }^{1, a, *} \text {, Hu Haiming }{ }^{1, b}
$$

${ }^{1}$ Institute of Problem Solving, Qingdao University of Science \&Technology, Pine ridge road, Qingdao ,China ${ }^{2}$ Department of Computing, Qingdao University of Science \& Technology, Pine ridge road ,Qingdao ,China a qdxufx@163.com, b huhm64@163.com

Keywords: Spring vent, The simulation analysis, Workbench

Abstract: Based on the theoretical calculation of the stiffness, stress and fatigue life of the spring vent, the spring fatigue life of three kinds of materials is simulated by the finite element method, and it is concluded that the service life of $65 \mathrm{Mn}$ materials is $59 \%$ and $41 \%$ higher than that of ordinary carbon steel (70) and Si bronze (QSi3-1) respectively.

Spring vent's main component is the spring, whose good or bad performance directly affect its exhaust performance and service life, Spring vent structure is shown in Figure 1. Spring material: Ordinary carbon spring wire, Grade 70; spring steel, grade 65Mn;silicon bronze, brand QSi3-1. The spring structure parameters are shown in Table 1.

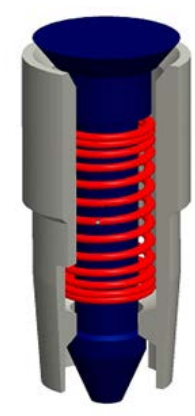

Figure 1 Structure diagram of Spring vent.

Table 1 Spring structural parameter.

\begin{tabular}{lc}
\hline \multicolumn{1}{c}{ Program } & Numerical $\quad$ value \\
\hline Spring middle diameter(D) & $1.6 \mathrm{~mm}$ \\
Material diameter (d) & $0.2 \mathrm{~mm}$ \\
Spring stroke( $\delta$ ) & $0.5 \mathrm{~mm}$ \\
Precompressed spring length $(\lambda)$ & $2 \mathrm{~mm}$ \\
Max Free Testable Length $(\mathrm{L})$ & $8.5 \mathrm{~mm}$ \\
Design cycle times & 10000 \\
\hline
\end{tabular}

\section{Theoretical analysis}

\subsection{The Theory of Stiffness}

The stiffness calculation formula of spring ${ }^{[1]}$ :

$k=\frac{G d^{4}}{8 n D^{3}}$

Where G-Shearing modulus of elasticity, GPa; 
n- Number of active coils;

D-Mean diameter of coil, mm;

d- Section diameter of spring, $\mathrm{mm}$.

By substituting the geometric parameters of the spring into equation (1), the stiffness $\mathrm{k}$ of the three material springs is obtained as shown in Table 2.

Table 2 Theoretical stiffness of three materials.

\begin{tabular}{ccc}
\hline Brand & $\begin{array}{c}\text { Shearing modulus of } \\
\text { elasticity }(\mathrm{GPa})\end{array}$ & $\begin{array}{c}\text { The theory of } \\
\text { stiffness(N/mm) }\end{array}$ \\
\hline 70 & 80 & 0.46 \\
$65 \mathrm{Mn}$ & 79 & 0.45 \\
QSi3-1 & 41 & 0.23 \\
\hline
\end{tabular}

\subsection{Analysis of The First Failure Point of Spring}

Because of the existence of spring wire spiral angle, the normal section of spring central axis is ellipse . In the function of spring spiral angle and curvature, the method of the center of a spring to the section stress distribution is shown in Figure 2, combined with the working principle of the spring vent, valve lever moves downward, helical springs are subjected to compressive forces, The compression force received during one stroke is increased to the maximum and the air vent sleeve is exhausted ;the spring vent is opened, and the maximum compression force is reduced to the installed compression force. The change in bending stress $\sigma$ at the normal section of the central axis of the spring also rapidly increases from a minimum to a maximum and then gradually decreases. This process is repeated with the working process of the spring air hole sleeve, so the first failure point of the spring is at the inner point of the normal section of the central axis of the spring. Theoretical analysis shows that under the repeated action of force, the point where the spring first breaks is located at the inner ring of the coil spring (internal point).

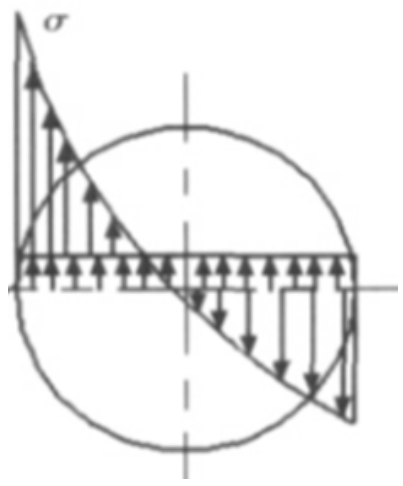

Figure 2 Force analysis of spring.

\subsection{Stress Analysis}

When the spring receives pressure from the valve stem, two types of shear stress are generated in the cross-section of the spring wire. One is the maximum shear stress directly generated by the shear stress, as shown in equation (2); the other is the maximum shear stress generated by the torque, as shown in equation (3).

$$
\begin{aligned}
& \tau_{1}=\frac{16 F_{\text {Max }}}{3 \pi d^{2}} \\
& \tau_{2}=\frac{8 D K^{\prime} F_{\text {Max }}}{\pi d^{3}}
\end{aligned}
$$

$K^{\prime}$ is the spring curvature coefficient, as shown in equation (4). 
$K^{\prime}=\frac{4 C-1}{4 C-4}+\frac{0.615}{C}$

Where $F_{\operatorname{Max}}$-The maximum force that the spring receives, as shown in equation (5).

$$
F_{\text {Max }}=\lambda_{\max } \mathrm{k}
$$

Where $\lambda_{\max }$-Spring maximum compression variable ,mm;

$$
\mathrm{C} \text { - Spring index }{ }^{[2]} \text {. }
$$

In this case $K^{\prime}=1.184$.

$C=\frac{D}{\mathrm{~d}}$

In this case $\mathrm{C}=8$.

The maximum shear stress is obtained by the superposition of two shear stresses .

$$
\tau_{\text {Max }}=\tau_{1}+\tau_{2}
$$

The bending stress of spring under load is shown in equation (7).The torsion force caused by the load is shown in equation (8).The stress limit of spring is shown in equation (9).

$$
\begin{gathered}
\sigma_{\mathrm{b}}=\frac{8 D K_{\mathrm{b}} F_{\max }}{\pi \mathrm{d}^{3}} \\
\sigma_{\tau}=\frac{8 D K_{\tau} F_{\max }}{\pi \mathrm{d}^{3}} \\
\sigma_{1 \mathrm{im}}=\sqrt{\left(\sigma_{\mathrm{b}}-\sigma_{\tau}\right)^{2}+4 \tau^{2}} \\
K_{\mathrm{b}}=1+\sin \alpha \\
K_{\tau}=\frac{2(4 C-1)}{4 C-4}
\end{gathered}
$$

In this case compensation factor : $\mathrm{K}_{\mathrm{b}}=1.13, \mathrm{~K}_{\mathrm{t}}=2.214$.

$\alpha$ : helical angle $\alpha$, set as $7.5^{\circ}$.

When the spring vent is in operation, the compression $\left(\lambda_{\min }\right)$ under the pre-installation load is 2 $\mathrm{mm}$, which is substituted into (2) to (8). The stress of the three materials is shown in Table 3.

Table 3 stress comparison of three materials.

\begin{tabular}{cccc}
\hline Material & 70 & $65 \mathrm{Mn}$ & QSi3-1 \\
\hline Kinds & & & \\
\hline$\sigma_{\max }$ & $1603 \mathrm{MPa}$ & $1568 \mathrm{MPa}$ & $822.5 \mathrm{MPa}$ \\
$\sigma_{\min }$ & $1036 \mathrm{MPa}$ & $1255 \mathrm{MPa}$ & $655.3 \mathrm{MPa}$ \\
$\tau_{\max }$ & $742 \mathrm{MPa}$ & $726 \mathrm{MPa}$ & $381 \mathrm{MPa}$ \\
$\tau_{\min }$ & $594 \mathrm{MPa}$ & $581 \mathrm{MPa}$ & $303 \mathrm{MPa}$ \\
\hline
\end{tabular}

\subsection{Fatigue Strength Check}

The spring vent is subjected to variable stress in the working process .For the spring under variable stress, and its fatigue strength safety factor is S:

$$
S=\frac{\tau_{0}+0.75 \tau_{\min }}{\tau_{\max }} \geq S_{\mathrm{p}}
$$


Where $\tau_{0}$ - Shear fatigue limit of spring material pulsating cycle, MPa;

$S_{P}$ - Spring fatigue strength design safety factor.

$$
\tau_{0}=0.45 \sigma_{b}
$$

The general value size is set to $S_{P}=1.3 \sim 1.7$. The fatigue safety factor $S$ of the three materials is shown in Table 4.

Table 4 Safety factor comparison of three materials.

\begin{tabular}{|l|c|c|c|}
\hline \multicolumn{1}{|c|}{ Material } & 70 & $65 \mathrm{Mn}$ & QSi3-1 \\
\hline Kinds & 1.74 & 1.87 & 1.78 \\
\hline
\end{tabular}

\section{Finite Element Analysis}

\subsection{The S-N Curve of The Material}

As shown in Figure 3, the S-N curve mainly describes the relationship between the fatigue strength and the fatigue life of a standard specimen under symmetrical cyclic alternating stress. The ordinate represents the fatigue strength of the material standard specimen, and the horizontal axis represents the fatigue life logarithm. When the pressure ratio is constant, the life span becomes larger as the stress range $s$ decreases, and the inversely proportional relationship increases. In the range of strength, the stress range is less than a certain limit value, and the life will tend to be infinite. Therefore, the material's S-N curve is not only limited to the fatigue analysis of the material, but also the basis for the life analysis.

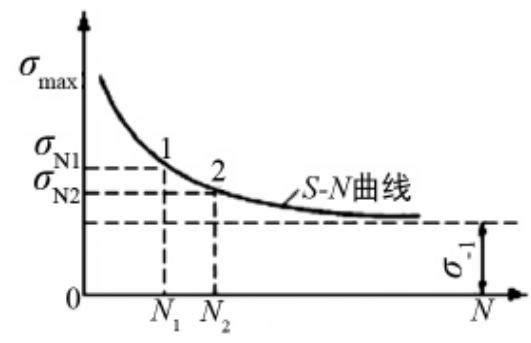

Figure 3 Fatigue Life Curve.

The Goodman formula ${ }^{[3]}$ is used for the conversion in the fatigue life calculation.

$$
\frac{\sigma_{\mathrm{a}}}{\sigma_{-1}}+\frac{\sigma_{\mathrm{m}}}{\sigma_{\mathrm{b}}}=1
$$

Where $\sigma_{\mathrm{a}}$-stress amplitude of fatigue limit, MPa;

$\sigma_{-1}$ - symmetric bending fatigue limit, MPa;

$\sigma_{\mathrm{m}}$-average stress, MPa .

In this case, the ordinary spring carbon steel wire (70) yield strength $\sigma_{\mathrm{s}}=1470 \mathrm{MPa}$, design life $\mathrm{N}_{\mathrm{i}}=10^{4}$ times, tensile strength $\sigma_{\mathrm{b}}=2100 \mathrm{MPa}$, cycle number $\mathrm{N}_{0}=10^{7}$, life expectancy index $\mathrm{m}$ $=9$. According to the actual operating condition of spring, compute the maximum stress ,minimum stress, life factor $K_{\mathrm{Ni}}$, fatigue limit $\sigma_{R V \mathrm{i}}, \sigma_{\mathrm{m}}, \sigma_{\mathrm{a}}$ and $\sigma_{-1}$.

$$
\sigma_{\mathrm{a}}=\frac{\left(\sigma_{\max }-\sigma_{\min }\right)}{2}
$$




$$
\begin{gathered}
\sigma_{\mathrm{m}}=\frac{\sigma_{\max }+\sigma_{\min }}{2} \\
\sigma_{-1}=\frac{\sigma_{\mathrm{a}}}{1-\frac{\sigma_{\mathrm{m}}}{\sigma_{\mathrm{b}}}} \\
K_{N \mathrm{i}}=\sqrt{\frac{N_{o}}{N_{\mathrm{i}}}} \\
\sigma_{R N \mathrm{i}}=K_{N \mathrm{i}} \sigma_{-1}
\end{gathered}
$$

When $\sigma_{R V \mathrm{i}} \geq \sigma_{\mathrm{s}}, \sigma_{R V \mathrm{i}}=\sigma_{\mathrm{s}}$; When $N_{\mathrm{i}} \geq N_{O}, N_{\mathrm{i}}=N_{0}$.

According to the above formula, the S-N curve data of carbon steel 70 under the alternating stress is obtained, as shown in Table 5.

Table 5 S-N curve data of normal carbon spring steel 70.

\begin{tabular}{lc}
\hline$N_{\mathrm{i}}($ time $)$ & $\sigma_{\mathrm{RNi}}(\mathrm{MPa})$ \\
\hline 10 & 1470 \\
100 & 1470 \\
1000 & 1470 \\
10000 & 1238.4 \\
100000 & 960.8 \\
1000000 & 744.2 \\
10000000 & 576 \\
100000000 & 576 \\
\hline
\end{tabular}

The S-N curve data of spring steel (65Mn) and silicon bronze (Qsi3-1) can also be obtained.

\subsection{Modeling}

A 3D solid model of the spring was set up ,the spring vent used in a tire mold factory was taken as an example, its characteristic parameters are as follows: material diameter $d=0.2 \mathrm{~mm}$, spring middle diameter $\mathrm{D}=1.6 \mathrm{~mm}$, effective number of turns $\mathrm{n}=8.5$, free height is $8.5 \mathrm{~mm}$.Save the established 3D model as a unique data file (x-t), read into ANSYS-Workbench to convert the 3D model, set the unit to $\mathrm{mm}$. Generate the geometry and recuperate.

\subsection{Add Model Properties}

According to the required materials, various parameters need to be added in the material warehouse. First, entering the material name in the interface of material parameter setting, and then adding the material density $(7800 \mathrm{~kg} / \mathrm{m} 3)$, modulus of elasticity $(\mathrm{E}=197900 \mathrm{Mpa})$ and Poisson's ratio in turn, finally adding the S-N data of the ordinary carbon spring steel 70,as shown in Figure 4.

When the spring is subjected to a forcing force, a coiling may occur within the spring .Under the function of the load, the change of the contact form between the spring rings is called the nonlinear problem of the boundary condition ${ }^{[4]}$. According to the actual operating conditions of the spring, the contact type is set to friction contact during the analysis ${ }^{[5]}$.In the process of calculating the simulation, setting the contact surface and the target surface so that they do not interfere with each other .The spring is compressed and deformed after being subjected to external load, and the contact pair is the self-contact between the number of effective circles, which is defined as frictional contact with a coefficient of friction of 0.1 .

\subsection{Divide The Grid}

In the process of simulation analysis, the grid division is very important, and reasonable division determines the accuracy of the calculation results .Selecting the spring 3D model, and defining the 
area of the grid unit, the grid size is set to 0.075 , the accuracy is set according to the default settings , click the generate command, and the grid partition progress will occur until the end .The finite element model of spring with meshed is shown in Figure 5.

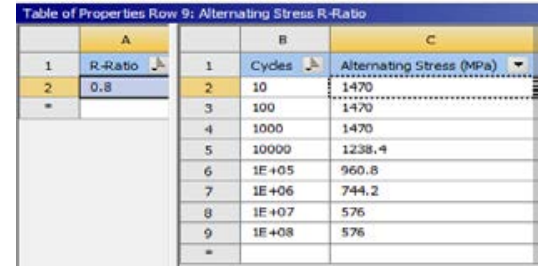

Figure 4 Material S-N data.

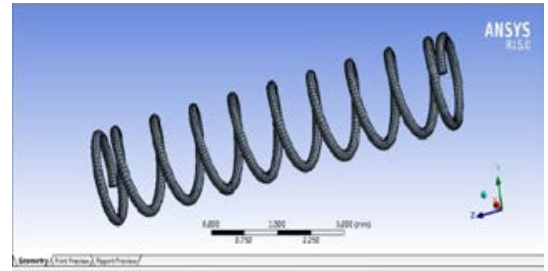

Figure 5 Finite element model of spring vent.

\subsection{Set Boundary Conditions}

According to the actual working condition of the spring, set boundary conditions for the upper support ring and the lower support ring .Select the lower support ring of the finite element spring model and apply a fixed constraint to limit the movement of the lower support ring in the X, Y, and $\mathrm{Z}$ directions .According to the working principle of the spring vent, subject to the vertical load of the valve stem, it is required to apply an axial forced displacement on the upper support ring.

The spring is compressed in the range of $2-2.5 \mathrm{~mm}$ in actual operation, the static loads take a maximum of $2.5 \mathrm{~mm}$, the specific position of the applied load is on the arc surface of the upper supporting ring of the spring, and the direction is axially vertical downward. Design spring life 10,000 times .Through the finite element simulation analysis of the spring, the support reaction force, shear stress and fatigue life are solved.

\subsection{Simulation Technique Solution}

After applying fixed constraints and load constraints in the model, the analysis results of the spring Maximum Shear Stress, branch reaction force, and fatigue life are obtained. The analysis results of the spring material of 70 steel is shown in Figure 6 .

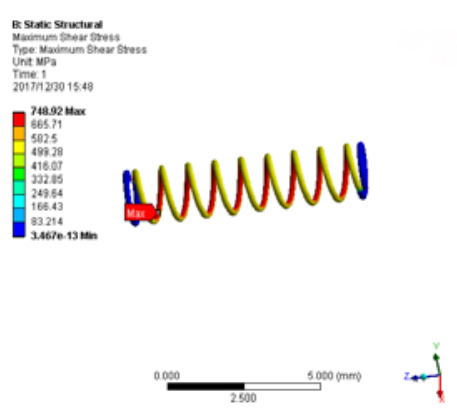

(1) Maximum shear stress

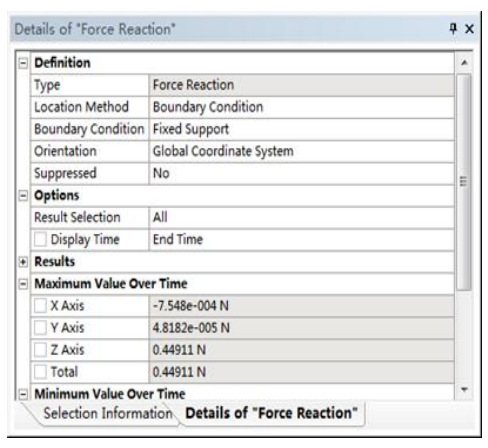

(2) Force reaction
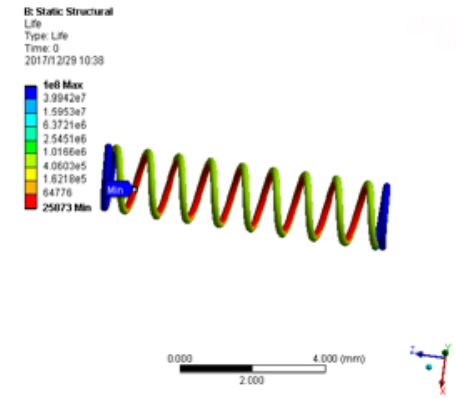

(3) Fatigue life

Figure 6 Analysis Contours of ordinary carbon spring steel (70). 


\section{Conclusion}

Table 6 The results are compared and analyzed.

\begin{tabular}{cccc}
\hline Material & 70Steel & $65 \mathrm{Mn}$ & QSi3-1 \\
\hline Phe theory of stiffness(N/mm) & 0.46 & 0.45 & 0.24 \\
Analytical stiffness(N/mm) & 0.449 & 0.447 & 0.237 \\
Stiffness error & $2 \%$ & $0.67 \%$ & $1.25 \%$ \\
Theoretical maximum shear stress (MPa) & 742.6 & 726.5 & 381 \\
Analyze the maximum shear stress (MPa) & 748.92 & 711.94 & 376 \\
Shear stress error & $0.8 \%$ & $2.00 \%$ & $1.31 \%$ \\
Force reaction & 0.449 & 0.446 & 0.592 \\
Minimum fatigue life & 25873 & 41322 & 29349 \\
\hline
\end{tabular}

1) The finite element calculation results are very close to the theoretical solutions, and the maximum error of the maximum shear stress and stiffness does not exceed 2\%, as shown in Table 6 .

2) Through the finite element analysis, the dangerous part of the spring is inside the first working circle,the simulated life of the maximum stress points of the three materials $(70,65 \mathrm{Mn}$, QSi3-1) exceeds the design life, which are 25873, 41322, and 29349, respectively. Among the three materials, spring steel (65Mn) has the longest service life and the smallest stiffness error.

\section{References}

[1] liu H.W. (2011)Mechanics of materials.Beijing ,China. Higher Education Press, 90.

[2] Pu L.G.,Chen G.D.(2013) Machine design. Beijing ,China. Higher Education Press, 394.

[3] An Z.W.,Bai X.Z.,Gao J.X..(2016) Residual life prediction model based on generalized $\sigma^{-N}$ surface. Journal of Hebei University of Science and Technology ,37,213-214.

[4] Yang M.Y., Zhang Y.H., Zhang Z.H., Sun X.P.. (2013) The application of finite element analysis technology in the research and development of spring of automobile steel plate with small slice variable section. Development \& Innovation of Machinery,26,96-98.

[5] Ling G.L..(2014) Ansys Workbench 15.0 from inception to mastery. Beijing ,China. Tsinghua University Press,97. 